\title{
Who presents more than once? Repeat abortion among women in Britain
}

\author{
Nicole Stone, ${ }^{1}$ Roger Ingham ${ }^{2}$
}

'Senior Research Fellow, Centre for Sexual Health Research, University of Southampton, Southampton, UK 2Professor of Health and Community Psychology, Centre for Sexual Health Research, University of Southampton, Southampton, UK

\section{Correspondence to}

Dr Nicole Stone, Centre for Sexual Health Research, School of Psychology, University of Southampton, Highfield, Southampton S017 1BJ, UK n.c.stone@soton.ac.uk

Received 10 November 2010 Accepted 7 March 2011 Published Online First 30 June 2011

\begin{abstract}
Background and methodology Around one in three sexually active women in Britain will have an abortion during their lifetime and a third of those women will experience more than one. Using data collected during the second National Survey of Sexual Attitudes and Lifestyles the characteristics of women who have presented for a second or subsequent abortion are compared to those women who have obtained only one. Results Results indicate that increased age and parity are key characteristics distinguishing between women who have experienced only one abortion and those women who have had more. Findings also reveal that those who have sought abortion on more than one occasion are more likely (than those who have had one abortion) to be Black, have left school at an earlier age, be living in rented accommodation, report an earlier age at first sexual experience, be less likely to have used a reliable method of contraception at sexual debut and report a greater number of sexual partners.
\end{abstract}

Discussion and conclusions it is well recognised that attendance at abortion services presents an important opportunity for the provision of individually tailored information regarding contraception to assist women avoid the need for subsequent procedures. However, differential use of abortion services may also indicate variations in knowledge levels, attitudes to risk, attitudes towards abortion, partner communication, gender power and differential access to services. Further research is required to clarify these potential relationships so that suitable health promotion activities can be developed.

\section{Background}

Data collated by the Office of National Statistics show that, in 2009, $1.7 \%$ of resident women of reproductive age in England and Wales underwent an abortion. This resulted in 189100 abortions of which $66 \%$ were first time procedures and $34 \%$ second or higher-order abortions. ${ }^{1}$ Data collected by the Information

\section{Key message points}

Around one in three women will have an abortion during their lifetime and a third of those women will experience more than one.

Women who have sought multiple abortions are more likely to have been younger at first sexual experience, be poor users of contraception at sexual debut and report a greater number of lifetime sexual partners.

- In the main, repeat abortions are not simply unintended pregnancies occurring near the beginning and then again at the very end of a woman's reproductive years.

Service Division Scotland show similar figures. As one would expect, the proportion of women obtaining a second or subsequent procedure increased markedly with age; for instance, among presenting women aged $18-24$ years, $28 \%$ had had at least one abortion before, while among women aged 30 and over, $43 \%$ had experience of a previous abortion, including $13 \%$ having had two or more. On the basis of the 2009 age-specific abortion rates it is possible to determine that just over one in three (35\%) women will have an abortion during their reproductive lives, and that a third (34\%) of those women will experience more than one. ${ }^{1}$

Ethnic differentials in repeat abortion are also evident. Across the entire age range, $48 \%$ of women of Black and Black British ethnic origin obtaining an abortion in 2009 were undergoing a second or subsequent procedure; this compares to $32 \%$ among the White population and $30 \%$ among women of Asian origin. ${ }^{1}$ Additionally, there is considerable geographic variation in repeat abortion; among presenting women aged under 25 years, the proportion attending for a second or subsequent procedure ranged from $13 \%$ in Merthyr Tydfil to $36 \%$ in Croydon, compared with 25\% across England and Wales as a whole. ${ }^{1}$

Previous authors have documented the stigmatisation women potentially face when requesting a second or subsequent 
abortion procedure. For example, those presenting more than once can be perceived as having difficulty in using contraception, lacking motivation to prevent unintended pregnancy, using abortion as a method of family planning or as being somehow different from other women in more fundamental ways, for example, regarding their fecundability. ${ }^{2-7}$ Negative attitudes continue to be evident despite the fact that previous studies have found that women presenting for repeat abortions either do not differ from women requesting their first abortion in their attempts to use contraception or are more likely to be actively using contraception at the time of conception. There is little evidence to suggest that women seeking more than one abortion are using it as a form of birth control..$^{7-16}$

As statistical models have clearly demonstrated, repeat abortion would occur even in populations where there are high levels of contraceptive use, due simply to the fact that unintended pregnancies occur even when contraception is being used. ${ }^{17}{ }^{18}$ As an illustration, annual pregnancy rates for typical use are around $3 \%$ for injectable users, $7 \%$ for users of the combined contraceptive pill, $14 \%$ for regular condom users and $24 \%$ for users of natural family planning. ${ }^{19}$ Based on the fecundability assumption of Tietze - that $20 \%$ of sexually active women would become pregnant in a month if no contraception were to be used - it is estimated that $35 \%$ of women who had abortions would experience at least one subsequent abortion within 2 years if they used a contraceptive method that had a typical user failure rate of $10 \%{ }^{4}$

National statistics and research into repeat abortion inevitably attract attention - little of it positive - with subsequent calls for the development of policies and programmes to help reduce the number of unintended pregnancies. Despite this, information regarding repeat abortion, and the women who undergo them, remains somewhat limited.

To improve understanding of the patterning of repeat abortion, the characteristics of women presenting for a second or subsequent abortion are generally compared to those women presenting for their first abortion. Although, typically, such studies have been conducted among opportunistic samples of women from a variety of backgrounds and within a variety of settings, they have consistently revealed a number of differences between the two groups.

In general, compared to women who are presenting for a first abortion, women who have previously had an abortion are older and therefore have had greater exposure to the risks of experiencing unintended pregnancy, are more likely to be unmarried, have children, engage in intercourse more frequently and with a greater number of partners, and report an earlier age at sexual debut. Racial and ethnic variations in repeat abortion have also been observed but any association with socioeconomic disadvantage, as defined through a variety of indicators, has been less conclusive. ${ }^{57-11 ~ 1620-23}$
A small number of studies have further examined the psychosocial precursors to repeat abortion and, although not currently supported through largescale repetition, suggest a possible link with physical abuse, violence, neglect and poor relationship development. $^{924-26}$

While the international research evidence suggests several important distinctions between women who have had multiple procedures and those who have had just one, only a small proportion of this research has been conducted in Great Britain. This paper aims to explore and expand upon some of the previously reported associations by using data collected from a representative sample of resident women in Britain; the second National Survey of Sexual Attitudes and Lifestyles (NATSAL2).

\section{Methodology}

NATSAL2, conducted in 2000-2001, collected sexual behaviour data from over 12000 men and women aged between 16 and 44 years living in Britain using a multistage stratified random sampling procedure. Data were collected with the use of face-to-face interviews and a computer-assisted self-completion survey tool. Full methodological details are reported elsewhere. ${ }^{27}$ Induced abortion variables available in the NATSAL2 dataset (accessed through the Economic and Social Data Service) included 'Had an abortion ever/last year/ last 5 years', 'Number of abortions ever' and 'Age at first/last abortion'.

To ensure the data were representative the NATSAL2 sample was weighted to adjust for unequal probabilities of selection and differential non-response. ${ }^{27}$ All statistical analyses were performed using Predictive Analytics SoftWare Statistics V18 (SPSS Inc., Chicago, IL, USA). Table 1 contains a listing of the demographic, lifestyle, sexual initiation, sexual history, contraceptive use and pregnancy history factors, both selectively extracted from and created using NATSAL2 survey responses, included in the analyses.

The analysis was conducted in two phases. Phase one compared women who had an abortion with those who had not, each categorical factor being independently examined to identify its bivariate association with abortion using the Chi-square test $\left(\chi^{2}\right)$ to test for any differences. The sample was subsequently split and a second phase of analyses conducted among just those women who had experience of abortion. Spacing between procedures was examined among women with experience of only two abortions and $\chi^{2}$ tests were performed, as before, to test for factorial differences between women who had experience of multiple abortion (two or more) and those who had only had a single procedure. On the basis of those findings, multivariable logistic regression modelling with forward stepwise selection was used to identify the key determinants of multiple abortion. Where both continuous and categorical explanatory variables of the same predictor were available (e.g. age 
Table 1 Factors included in the bivariate and logistic regression modelling

\begin{tabular}{|c|c|}
\hline Category & Factors \\
\hline $\begin{array}{l}\text { Demographicl } \\
\text { background }\end{array}$ & $\begin{array}{l}\text { Age (continuous, grouped), region, ethnicity, religion, } \\
\text { social deprivation, social class, tenure, marital } \\
\text { status, family formation, educational achievement, } \\
\text { schooling, parental openness }\end{array}$ \\
\hline Lifestyle & $\begin{array}{l}\text { Alcohol consumption, smoking behaviour, body } \\
\text { mass index, drug usage }\end{array}$ \\
\hline Sexual initiation & $\begin{array}{l}\text { Age at first sexual experience (continuous, grouped), } \\
\text { age at first intercourse (continuous, grouped), sexual } \\
\text { competency }\end{array}$ \\
\hline Sexual history & $\begin{array}{l}\text { Number of partnerships (ever, last year, last } 5 \\
\text { years), concurrent partnerships, sexually transmitted } \\
\text { infection history }\end{array}$ \\
\hline $\begin{array}{l}\text { Contraceptive } \\
\text { use }\end{array}$ & $\begin{array}{l}\text { Contraceptive use at first intercourse (ever, most } \\
\text { recent partner), typical use, occasions of unprotected } \\
\text { intercourse, use of condoms }\end{array}$ \\
\hline $\begin{array}{l}\text { Pregnancy } \\
\text { history }\end{array}$ & $\begin{array}{l}\text { Parity, number of children, fatherhood, births prior } \\
\text { to first abortion, age at last abortion/first abortion } \\
\text { (continuous, grouped), experience of spontaneous } \\
\text { abortion and stillbirth }\end{array}$ \\
\hline
\end{tabular}

at first abortion) both were scrutinised in the model, independently of one another. Appropriate checks for multicollinearity were also made. The final, 'best fit', model is presented.

\section{Results}

\section{Description of the sample}

The weighted subsample consisted of 5625 female respondents aged 16-44 years who had engaged in sexual intercourse on at least one occasion. Some 71\% of women interviewed had experience of carrying at least one pregnancy to term, 31\% reported having had a spontaneous abortion or stillbirth and $18 \%$ of the sexually active women reported ever having an induced abortion $(n=1003)$; $8 \%$ of women aged $16-19$ years at the time of interview, 19\% of women aged 25-29 and 21\% of women aged 35-39 (Table 2).

At the time of their first abortion, $70 \%$ of women were nulliparous (had not previously given birth), $42 \%$ of respondents were aged 19 years or under and 29\% were aged 20-24 years (Table 3).

\section{Characteristics associated with ever having an abortion}

At the bivariate level, incidence of ever experiencing an abortion was not found to vary significantly by level of deprivation. Significant variation did exist, however, by ethnic grouping, family structure until age 16 years, age of sexual debut and sexual competency at first intercourse (derived from variables on the reasons for and circumstances surrounding first intercourse ${ }^{28}$ ). A third of women classified as Black reported ever having an abortion compared to $18 \%$ of White women $\left(\chi^{2}=\right.$ $26.8, \mathrm{df}=4, p<0.001)$, while $26 \%$ of women who did not live with either of their natural parents up until the age of 16 years reported having an abortion compared to $17 \%$ of women living with both natural parents $\left(\chi^{2}\right.$
Table 2 Percentage of sexually experienced 16-44year-old women reporting ever having an abortion, by selected characteristics

\begin{tabular}{|c|c|c|c|}
\hline \multirow[b]{2}{*}{ Characteristic } & \multicolumn{2}{|c|}{$\begin{array}{l}\text { Ever had an } \\
\text { abortion (\%) }\end{array}$} & \multirow[b]{2}{*}{$n$} \\
\hline & Yes & No & \\
\hline All respondents & 18.0 & 82.0 & 5567 \\
\hline \multicolumn{4}{|l|}{ Age at interview (years) } \\
\hline $16-19$ & 8.1 & 91.9 & 472 \\
\hline $20-24$ & 13.6 & 86.4 & 788 \\
\hline $25-29$ & 18.6 & 81.4 & 1021 \\
\hline $30-34$ & 20.8 & 79.2 & 1166 \\
\hline $35-39$ & 20.5 & 79.5 & 1128 \\
\hline $40-44$ & 19.7 & 80.3 & 992 \\
\hline \multicolumn{4}{|l|}{ Ethnicity } \\
\hline White & 17.5 & 82.5 & 5142 \\
\hline Black & 33.1 & 66.9 & 139 \\
\hline Indian & 19.0 & 81.0 & 84 \\
\hline Pakistani and Bangladeshi & 10.9 & 89.1 & 46 \\
\hline Chinese, other Asian and Other & 23.6 & 76.4 & 156 \\
\hline \multicolumn{4}{|l|}{ Family structure until age 16 years } \\
\hline Both natural parents & 16.8 & 83.2 & 4327 \\
\hline One natural parent & 21.6 & 78.4 & 1067 \\
\hline Neither natural parent & 26.6 & 73.4 & 173 \\
\hline \multicolumn{4}{|l|}{ Age at sexual debut (years) } \\
\hline $13-15$ & 26.0 & 74.0 & 1199 \\
\hline $16-17$ & 18.0 & 82.0 & 2422 \\
\hline $18-19$ & 15.6 & 84.4 & 1222 \\
\hline $20-24$ & 9.1 & 90.9 & 584 \\
\hline $25+$ & 3.8 & 96.2 & 106 \\
\hline \multicolumn{4}{|l|}{ Sexual competency } \\
\hline Competent & 12.6 & 87.4 & 2287 \\
\hline Not competent & 21.9 & 78.1 & 3192 \\
\hline
\end{tabular}

$=19.3, \mathrm{df}=2, p<0.001)$. A quarter $(26 \%)$ of women who experienced first sexual intercourse under the age of 16 years had had an abortion, compared to $18 \%$ of women whose first intercourse occurred at ages 16-17 years and $16 \%$ of women who became sexually active between the ages of 18 and 19 years $\left(\chi^{2}=103.0, \mathrm{df}=\right.$ $4, p<0.001$ ), while $13 \%$ of women classified as sexually competent at sexual debut had sought an abortion as opposed to $22 \%$ who were considered not competent $\left(\chi^{2}=77.3, \mathrm{df}=1, p<0.001\right)$.

\section{Characteristics associated with having more than one abortion}

Among women reporting experience of abortion, just under one-fifth had had more than one procedure, with just under a quarter of those women reporting three or more abortions (Table 3).

The median time that lapsed between first and second procedures, among women with experience of only two abortions, was 41 months (interquartile range 80 months) with $17 \%$ of women undergoing a 
second abortion within 1 year of their first abortion and a third within 2 years. At the other end of the spectrum, $10 \%$ of these women experienced at least a 15-year time lapse between procedures (Figure 1).

A range of indicators were found to be associated with experience of multiple abortion (two or more) as compared to a single procedure at the bivariate level. These included, among others, poor contraceptive use at first intercourse with most recent partner, recent unsafe sexual activity, increased number of lifetime sexual partners, marital status and cohabiting partnerships, greater parity, lower educational achievement, experience of spontaneous abortion and/or stillbirth and sexually transmitted infection clinic attendance.

Table 3 Percentage distribution of 16-44-year-old women who have experience of abortion, by selected characteristics

\begin{tabular}{lrr}
\hline Characteristic & \multicolumn{1}{c}{$\%$} & $\boldsymbol{n}$ \\
\hline Age at first abortion (years) & & \\
$<16$ & 5.4 & 53 \\
$16-17$ & 18.1 & 177 \\
$18-19$ & 18.5 & 181 \\
$20-24$ & 28.6 & 279 \\
$25-29$ & 17.1 & 167 \\
$30-34$ & 8.2 & 80 \\
$35-39$ & 3.2 & 31 \\
$40+$ & 0.9 & 8 \\
All ages & 100.0 & 976 \\
Number of abortions ever & & 810 \\
1 & 80.8 & 148 \\
2 & 14.8 & 45 \\
$3+$ & 4.5 & 1003 \\
1 or more & 100.0 & \\
\hline Missing responses: Age at first abortion $(n=27)$. &
\end{tabular}

At the multivariate level, the factors found to be predictive of a woman experiencing a second or subsequent abortion if she had previously undergone a termination of pregnancy are shown in the final model displayed in Table 4. The results show that the odds of a woman having obtained more than one abortion increase with age at last procedure, as would be expected. Parity was also shown to be a key factor, with experience of a live birth prior to first abortion reducing the likelihood of a woman having obtained more than one abortion by $88 \%$ while, conversely, the odds of repeat abortion increased incrementally with the number of natural children ever born.

Compared with women who had experienced only one abortion, women who had undergone repeat abortions were more likely to have been younger at first sexual experience (e.g. kissing, cuddling or petting), be poor users of contraception at sexual debut and report a greater number of lifetime sexual partners (anyone with whom they had ever had oral, vaginal or anal sex). As shown in Table 4, once all other factors have been accounted for, women who reported not using any method of contraception - or who used a traditional method such as natural family planning or withdrawal - at first sex were roughly twice as likely to have experienced more than one abortion than those women who had used a modern method. Additionally, women who reported five or more lifetime sexual partners were twice as likely to have had a repeat abortion.

Black, as compared to White women, were almost four times more likely to have sought more than one abortion [odds ratio (OR) 3.76]. Further, relative to women who left school aged 17 years or older, women who left school aged 16 years had over twice the odds of experiencing a repeat abortion, regardless of whether or not they gained any

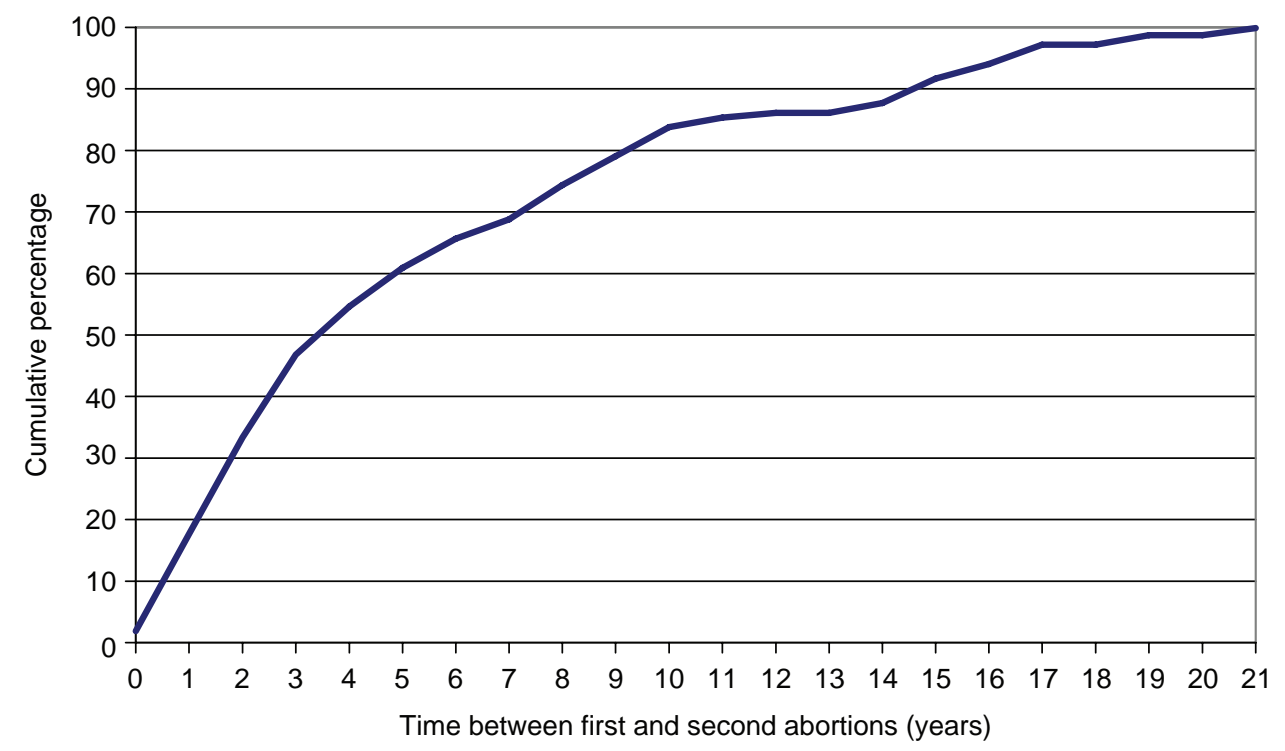

Figure 1 Cumulative percentage of women experiencing two abortions by elapsed time between procedures. 
qualifications prior to leaving (ORs of 2.36 and 2.61, respectively).

Finally, women who at the time of interview were living in rented accommodation, as opposed to owning their own home outright or with a mortgage, were almost twice as likely to have had more than one abortion (OR 1.96), and, while deprivation was additionally found to be associated with incidence of repeat abortion, no clear incremental pattern was apparent.

\section{Discussion and conclusions}

Women having more than one abortion are generally older. This is not surprising given that older women

Table 4 Odds ratios and confidence intervals from logistic regression analyses predicting the effects of various characteristics on the likelihood of repeat abortion among women who have had prior experience of abortion

\begin{tabular}{|c|c|c|c|c|}
\hline Characteristic & $n$ & OR & $p$ & $95 \% \mathrm{Cl}$ \\
\hline Age at time of interview & 1003 & 0.96 & * & $0.92-1.00$ \\
\hline \multicolumn{5}{|l|}{ Index of multiple deprivation } \\
\hline First quintile (least deprived) & 167 & 0.51 & * & $0.26-1.00$ \\
\hline Second quintile & 212 & 0.80 & & $0.45-1.42$ \\
\hline Third quintile & 200 & 0.36 & ** & $0.18-0.70$ \\
\hline Fourth quintile & 210 & 0.68 & & $0.38-1.22$ \\
\hline Fifth quintile (most deprived) [ref] & 209 & 1.00 & & \\
\hline Age at first sexual experience & 998 & 0.87 & ** & $0.80-0.95$ \\
\hline \multicolumn{5}{|l|}{ Ethnicity } \\
\hline White [ref] & 900 & 1.00 & & \\
\hline Black & 46 & 3.76 & ** & $1.61-8.80$ \\
\hline Indian & 16 & 1.27 & & $0.22-7.28$ \\
\hline Pakistani and Bangladeshi & 5 & 4.19 & & $0.39-44.5$ \\
\hline Chinese, other Asian and Other & 36 & 2.80 & * & $1.15-6.82$ \\
\hline Number of natural children & 1003 & 1.33 & ** & \\
\hline \multicolumn{5}{|l|}{ Education } \\
\hline Left school at 16 with no qualifications & 161 & 2.61 & $* *$ & $1.37-4.99$ \\
\hline Left school at 16 with some qualifications & 309 & 2.36 & $* * *$ & $1.46-3.81$ \\
\hline Left school at 17+ [ref] & 529 & 1.00 & & \\
\hline \multicolumn{5}{|l|}{ Housing tenure } \\
\hline Own outright/with mortgage or loan [ref] & 598 & 1.00 & & \\
\hline Rented accommodation & 402 & 1.96 & ** & $1.27-3.03$ \\
\hline \multicolumn{5}{|l|}{ Contraceptive use at first intercourse } \\
\hline Condom (+ other modern method) [ref] & 470 & 1.00 & & \\
\hline Other reliable & 122 & 0.76 & & $0.38-1.56$ \\
\hline Non-reliable (withdrawal/rhythm) & 86 & 1.96 & * & $1.00-3.87$ \\
\hline Non-use & 314 & 2.04 & ** & $1.25-3.32$ \\
\hline \multicolumn{5}{|l|}{ Number of sexual partners } \\
\hline$\leq 4$ [ref] & 289 & 1.00 & & \\
\hline$\geq 5$ & 701 & 2.13 & $* *$ & $1.25-3.63$ \\
\hline \multicolumn{5}{|l|}{ Birth prior to first abortion } \\
\hline No [ref] & 693 & 1.00 & & \\
\hline Yes & 291 & 0.12 & $* * *$ & $0.07-0.22$ \\
\hline \multicolumn{5}{|l|}{ Age at last abortion (years) } \\
\hline$<16$ & 46 & 0.01 & $* *$ & $0.00-0.18$ \\
\hline $16-17$ & 139 & 0.12 & $* * *$ & $0.05-0.30$ \\
\hline $18-19$ & 153 & 0.22 & $* * *$ & $0.10-0.50$ \\
\hline 20-24 [ref] & 282 & 1.00 & & \\
\hline $25-29$ & 207 & 2.49 & $* *$ & $1.46-4.25$ \\
\hline $30-34$ & 108 & 6.20 & $* * *$ & $3.12-12.3$ \\
\hline $35-39$ & 63 & 7.53 & $* * *$ & $3.18-17.8$ \\
\hline Constant & & 1.45 & & \\
\hline-2 log likelihood & & 643.29 & & \\
\hline df & & 26 & & \\
\hline
\end{tabular}


have had more years of exposure to the risk of experiencing an unintended pregnancy. Parity is also a key distinguishing factor; for every additional child born to a woman there is a 33\% increase in the odds of experiencing more than one abortion. Yet timing of these births is also highly important; for instance, if a woman experiences a birth prior to her first abortion the likelihood of her having a subsequent abortion is reduced by $88 \%$, after controlling for all other factors.

The analysis presented here also reveals that compared with women who have had one abortion and after controlling for all other factors, those who have obtained multiple abortions are more likely to be Black as opposed to White, to have left school at an earlier age, to be living in rented accommodation, to report an earlier age at first sexual experience, to have been less likely to have used a reliable method of contraception at sexual debut and to report a greater number of lifetime sexual partners.

The failure of effective contraception obviously has a central role in the occurrence of unintended pregnancy and subsequent abortion; indeed, several studies suggest modern method usage rates of around $50 \%$ among women presenting for abortion. ${ }^{20} 2930$ Unfortunately, NATSAL2 did not collect comparable data; however, it does appear that early sexual competency, contraceptive use at sexual debut and contraceptive use at first intercourse with a new partner (see bivariate analyses) could impact on subsequent effective contraceptive use practices and, as such, be used as an advance indicator of potential risk. Similarly, is it evident that women who engage in sexual behaviour from an early age and those who have greater numbers of sexual partners are also at increased risk of experiencing repeat abortion.

Although social deprivation was not found to clearly predict the occurrence of repeat abortion in the regression model, this is perhaps not so surprising for two main reasons. First, it may be redundant due to the inclusion in the model of proxy indicators such as housing tenure, ethnicity and early school leaving age and, second, due to the complex interplay between deprivation, unintended pregnancy, pregnancy decision-making and subsequent likelihood that an unintended pregnancy may result in a live birth rather than an abortion.

It could be reasonably assumed that a frequent pattern of repeat abortion would be that women experience an unintended pregnancy and abortion near the start of their reproductive lives, go through a period of safe sexual practices and planned childbearing and then experience a subsequent unintended pregnancy. If so, one would expect a lengthy delay between abortion procedures; however, half of all second abortions reportedly occurred within 41 months of the previous procedure, and only $10 \%$ occurred more than 15 years apart. This suggests that, for the majority of women, such abortions are clearly not unintended pregnancies occurring at the extremes of their reproductive careers.
It seems there are more complex patterns of delay and spacing prior to completion of their childbearing goals, and indicates likely context or situational specific barriers to the prevention of unintended pregnancy, including poor partner communication, planning and a possible lack of control in sexual situations. Regrettably, from NATSAL2 it is not possible to determine what proportion of these relatively close repeat abortions occur to women prior to entering a stable relationship.

What is interesting to note is that despite legal and cultural differences between Britain and the USA, the median time span of 41 months between first and second procedures is remarkably similar to the 44-month span between all procedures as reported in the 2002 US National Survey of Family Growth. ${ }^{11}$

Although it is recognised that the analyses presented here are based on a relatively small sample of women reporting experience of an abortion (weighted $n=1003$ ), the sampling techniques employed during NATSAL2 and subsequent weighting should mean that the final respondent sample is representative of British women and there is no reason why the relationships between variables cannot be accepted with confidence. What is less certain, however, is the level of under-reporting of abortion that occurred during data collection (in the light of the sensitivity surrounding the issue) and the reliability of respondent recall of situations and events that may have occurred some time previously. ${ }^{11}$ 3132 Comparison with national statistics does tend to suggest a possible degree of under-reporting, although it is not immediately clear how any associated stigma would co-vary with the variables of interest.

Although the purpose of this paper was not to draw negative attention to women who present more that once or to the incidence of multiple abortion procedures themselves, it is possible to build a profile of women who are likely to present at abortion services on more than one occasion. Through doing so, support can be focused towards assisting such women to avoid the need for multiple visits, and the findings presented here point to some areas where attention might profitably be directed in terms of trying to reduce the incidence of repeat abortions. Clearly, differential use of abortion services may indicate one or more of variations in knowledge levels, attitudes to risk, attitudes towards abortion, partner communication, gender power and differential access to services. Further research will be required to clarify these potential relationships so that suitable health promotion activities can be developed.

In any event, it is well recognised that attendance at abortion services presents an important opportunity for the provision of detailed, individually tailored information regarding contraception to assist all women to avoid the need for subsequent procedures. Contraceptive counselling and, where appropriate, provision in abortion clinics is increasing in scope and will, it is assumed, lead to a reduction in second and subsequent procedures. ${ }^{1433}$ 
Indeed, since not every woman will attend an abortion service, such information should be provided as a matter of routine to all women; schools and colleges are ideal settings for such interventions. The provision of adequate knowledge, as well as developing the competencies to enable women to put their knowledge and wishes into practice, are the least that all young women should expect from the education system.

Acknowledgements The authors would like to thank the National Centre for Social Research for granting them permission to access the NATSAL2 data through the Economic and Social Data Service.

\section{Competing interests None.}

Provenance and peer review Not commissioned; externally peer reviewed.

\section{References}

1 Department of Health. Abortion Statistics, England and Wales: 2009 (Statistical Bulletin, 2010/1). London, UK: Department of Health, 2010.

2 Rovinsky JJ. Abortion recidivism. A problem in preventive medicine. Obstet Gynecol 1972;39:649-659.

3 Weinstein M, Wood JW, Stoto MA, et al. Components of agespecific fecundability. Popul Stud (Camb) 1990;44:447-467.

4 Tietze C. The 'problem' of repeat abortions. Fam Plann Perspect 1974;6:148-150.

5 Millar WJ, Wadhera S, Henshaw SK. Repeat abortions in Canada, 1975-1993. Fam Plann Perspect 1997;29:20-24.

6 Tietze C. Repeat abortions - why more? Fam Plann Perspect 1978;10:286-288.

7 Rowlands S. More than one abortion. J Fam Plann Reprod Health Care 2007;33:155-158.

8 Howe B, Kaplan HR, English C. Repeat abortions: blaming the victims. Am J Public Health 1979;69:1242-1246.

9 Fisher WA, Singh SS, Shuper PA, et al. Characteristics of women undergoing repeat induced abortion. CMAJ 2005;172:637-641.

10 Berger C, Gold D, Andres D, et al. Repeat abortion: is it a problem? Fam Plann Perspect 1984;16:70-75.

11 Jones R, Singh S, Finer L, et al. Repeat Abortion in the United States. New York, NY: Guttmacher Institute, 2006.

12 Callan VJ. Repeat and first abortion seekers: single women in Brisbane, Australia. J Biosoc Sci 1983;15:217-222.

13 Shepard MJ, Bracken MB. Contraceptive practice and repeat induced abortion: an epidemiological investigation. J Biosoc Sci 1979;11:289-302.

14 Garg M, Singh M, Mansour D. Peri-abortion contraceptive care: can we reduce the incidence of repeat abortions? J Fam Plann Reprod Health Care 2001;27:77-80.
15 Steinhoff PG, Smith RG, Palmore JA, et al. Women who obtain repeat abortions: a study based on record linkage. Fam Plann Perspect 1979;11:30-38.

16 Westfall JM, Kallail KJ. Repeat abortion and use of primary care health services. Fam Plann Perspect 1995;27:162-165.

17 Tietze C, Bongaarts J. Repeat abortion in the United States: new insights. Stud Fam Plann 1982;13:373-9, 384.

18 Tietze C, Jain AK. The mathematics of repeat abortion: explaining the increase. Stud Fam Plann 1978;9:294-299.

19 Fu H, Darroch JE, Haas T, et al. Contraceptive failure rates: new estimates from the 1995 National Survey of Family Growth. Fam Plann Perspect 1999;31:56-63.

20 St John H, Critchley H, Glasier A. Can we identify women at risk of more than one termination of pregnancy? Contraception 2005;71:31-34.

21 Heikinheimo O, Gissler M, Suhonen S. Age, parity, history of abortion and contraceptive choices affect the risk of repeat abortion. Contraception 2008;78:149-154.

22 Prager SW, Steinauer JE, Foster DG, et al. Risk factors for repeat elective abortion. Am J Obstet Gynecol 2007;197:575.e1-575.e6.

23 Osler M, David HP, Morgall JM. Multiple induced abortions: Danish experience. Patient Educ Couns 1997;31:83-89.

24 Silverman JG, Decker MR, McCauley HL, et al. Male perpetration of intimate partner violence and involvement in abortions and abortion-related conflict. Am J Public Health 2010;100:1415-1417.

25 Aston G, Bewley S. Abortion and domestic violence. Obstet Gynecol 2009;11:163-168.

26 Jacoby M, Gorenflo D, Black E, et al. Rapid repeat pregnancy and experiences of interpersonal violence among low-income adolescents. Am J Prev Med 1999;16:318-321.

27 Johnson AM, Mercer CH, Erens B, et al. Sexual behaviour in Britain: partnerships, practices, and HIV risk behaviours. Lancet 2001;358:1835-1842.

28 Wellings K, Nanchahal K, Macdowall W, et al. Sexual behaviour in Britain: early heterosexual experience. Lancet 2001;358:1843-1850.

29 Das S, Adegbenro A, Ray S, et al. Repeat abortion: facts and issues. J Fam Plann Reprod Health Care 2009;35:93-95.

30 Henshaw SK, Kost K. Abortion patients in 1994-1995: characteristics and contraceptive use. Fam Plann Perspect 1996;28:140-7, 158.

31 Wilcox AJ, Horney LF. Accuracy of spontaneous abortion recall. Am J Epidemiol 1984;120:727-733.

32 Udry JR, Gaughan M, Schwingl PJ, et al. A medical record linkage analysis of abortion underreporting. Fam Plann Perspect 1996;28:228-231.

33 Yassin AS, Cordwell D. Does dedicated pre-abortion contraception counselling help to improve post-abortion contraception uptake? J Fam Plann Reprod Health Care 2005;31:115-116. 